For Table of Contents use only

\title{
Nanofibers from Water-Extractable Melt-Blown Immiscible Polymer Blends
}

Zaifei Wang, Xiaotun Liu, Christopher W. Macosko*, Frank S. Bates*

Department of Chemical Engineering and Materials Science, University of Minnesota, Minneapolis, MN 55455

* Address correspondence to: macosko@umn.edu, bates001@umn.edu.

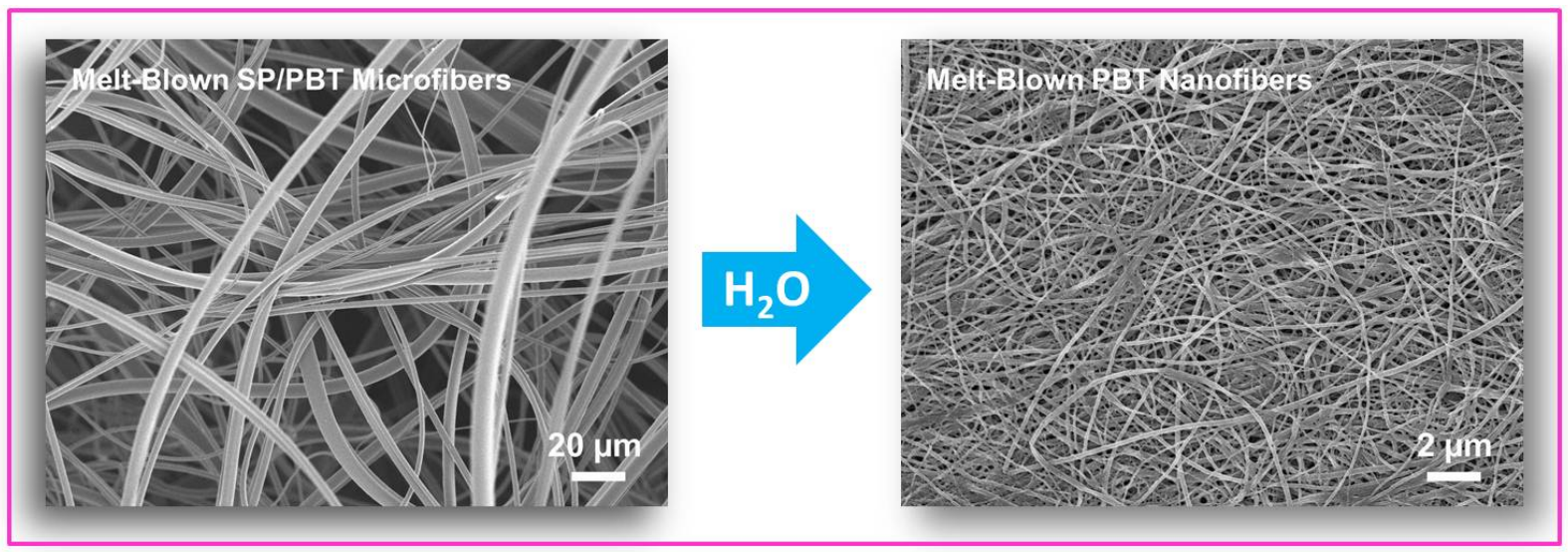




\title{
Nanofibers from Water-Extractable Melt-Blown \\ Immiscible Polymer Blends
}

Zaifei Wang, Xiaotun Liu, Christopher W. Macosko*, Frank S. Bates*

Department of Chemical Engineering and Materials Science, University of Minnesota, Minneapolis, MN 55455

*Corresponding authors: macosko@umn.edu, bates001@umn.edu.

\begin{abstract}
Nanofibers were prepared from water-extractable melt-blown immiscible polymer blends containing a commercial sulfopolyester (SP) as the sacrificial phase. Application of the water-dispersible SP eliminates issues associated with organic solvents, providing a facile, economic, and environment-friendly approach to high throughput fabrication of melt-blown nanofibers with an average diameter as small as $66 \mathrm{~nm}$. Moreover, this approach offers a new route to prepare multilayer melt-blown nano-/micro-fiber composites. We demonstrate the fabrication of porous double-layer melt-blown PBT nano-/micro-fiber composites by tuning the collection time of the melt-blown SP/PBT blend fibers. Such materials are potentially useful for filtration media.
\end{abstract}

Keywords: Nanofibers, Melt-Blown, Water-Extractable Blends 


\section{Introduction}

Nonwoven nanofibers have found uses in filtration,[1-4] performance apparel,[5,6] biological tissue engineering,[7-9] medical textiles,[10,11] and composite materials.[12,13] Several techniques can be applied to fabricate nonwoven nanofibers, such as electrospinning,[14] melt spinning,[15] forcespinning,[16] and melt blowing.[17] Among these techniques, electrospinning has attracted the most attention owing to the ability to produce fibers with an average diameter of less than $100 \mathrm{~nm}$. According to the database of Web of Science, there were nearly 1000 research articles associated with electrospun nanofibers in 2014. However, this method is costly, has relatively low productivity,[18] and is difficult to scale up. The required use of solvents raises additional concerns.[19]

We have reported a new approach to fabricate nanofibers from melt-blown fiber-in-fiber polymer blends.[20] Melt blowing immiscible polymer blends that contain spherical domains leads to a hierarchical nanofibers-in-microfiber structure, and subsequent extraction of the matrix polymer with an appropriate solvent exposes the nanofibers. For example, we have produced poly(ethylene-co-chlorotrifluoroethylene) (ECTFE) nanofibers with an average diameter of 70 $\mathrm{nm}$ after washing away the continuous poly(butylene terephthalate) (PBT) matrix using trifluoroacetic acid (TFA).[20] This new method has the potential to be applied for the mass production of nanofibers. However, the use of organic solvents such as TFA to remove the carrier polymer necessitates solvent handling and recycling, adding to the cost of manufacturing and incurring potential environmental challenges. Application of water-extractable polymers, either water-soluble or water-dispersible, as the sacrificial matrix is an attractive approach to mitigating these shortcomings. 
However, most water soluble polymers suffer from degradation at the high temperatures appropriate for melt blowing. Tran et al. recently reported conjugate melt spinning of poly(lactic acid) (PLA) and poly(vinyl alcohol) (PVA) blends, using PVA as the "sea" and PLA the "islands".[21] After dissolving the PVA with water, they obtained PLA nanofibrils with an average diameter of $60 \mathrm{~nm}$. In order to minimize the thermal degradation of PVA, they kept the spinning temperature below $200{ }^{\circ} \mathrm{C}$. At this temperature the viscosity was too high for melt blowing. Although various approaches such as plasticization[22-26] and blending[27,28] have been developed to stabilize PVA for thermal processing, it is still challenging to conduct melt blowing of this material at a temperature where an optimal viscosity is attained. Nevertheless, Nishio et al patented a technique for generating nanofibers (reportedly $5-500 \mathrm{~nm}$ in diameter but without corroborating fiber images) from melt-blown PVA-containing polymer blends at $230{ }^{\circ} \mathrm{C} .[29]$ The PVA they employed had a degree of polymerization of 400 and a saponification value of $62 \%$. Curiously, they did not discuss thermal degradation of their PVA. Other commercial water-soluble polymers such as poly(ethylene oxide), poly(acrylic acid), poly(methacrylic acid), and poly(vinyl pyrrolidone) suffer from the same trade-offs between thermal degradation and optimal viscosity for melt blowing.[30-33]

We report in this communication that nanofibers can be achieved from melt-blown polymer blends containing a thermally stable water-dispersible polymer, sulfopolyester (SP) (AQ48 Ultra, Eastman Chemical Company, US) as the sacrificial phase. The molecular structure of SP is shown in Scheme 1. This new method enables us to use water to expose PBT nanofibers after melt blowing, which not only eliminates issues associated with organic solvents but also provides another route to prepare multilayer nano-/micro-fiber composites. 
<smiles>CC(C)OCC1CCC(COC(=O)c2cc(C(=O)OCCOCCOC(=O)c3cccc(C(=O)O)c3)cc([N+](=O)[O-])c2)CC1</smiles>

Scheme 1. Molecular structure of sulfopolyester (SP).

2. Experimental details and characterizations

Experimental details and characterization methods are supplied in the Supporting Information.

\section{Results and discussion}

PBT was blended as the minority phase (30 wt $\%$ ) with SP denoted SP/PBT(70/30). The morphology of the polymer blends were characterized using scanning electron microscopy (SEM) (see Supporting Information). As shown in the representative SEM image in Figure 1, PBT appears as approximately spherical droplets dispersed in the SP matrix, consistent with the immiscible nature of this blend. A geometric average diameter $\left(D_{\text {av }}\right)$ of $1.55 \mu \mathrm{m}$ and a geometric standard deviation (GSD) of 1.58 were obtained by log-normal fitting using OriginLab software. This morphology reflects a much finer droplet size than we reported in a PS/PBT_70/30 blend employed in a previous study, $\left(D_{\mathrm{av}}=15.2 \mu \mathrm{m}\right),[20]$ most likely due to a transesterification reaction, which should lower the interfacial tension between SP and PBT.[34]

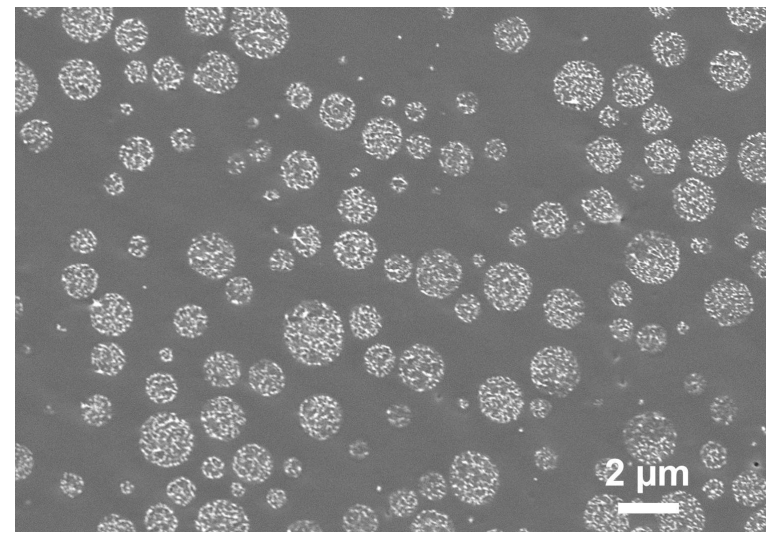

(a)

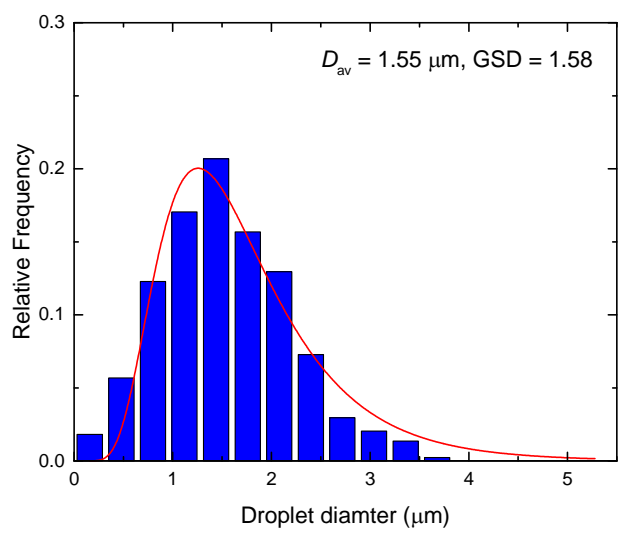

(b) 
Figure 1. (a) SEM image of cryo-fractured SP/PBT(70/30) blend, (b) Statistical distribution of PBT droplets in the SP matrix.

The SP/PBT(70/30) blend was melt blown at $265{ }^{\circ} \mathrm{C}$ using our lab-scale melt blowing apparatus (details of melt blowing are provided in Supporting Information).[17,35] Figure 2(a) shows the morphology of the resulting fibers. About $400-500$ fibers were measured and the results were fit with a log-normal distribution function, resulting in a geometric average fiber diameter $\left(d_{\mathrm{av}}\right)$ of $2.35 \mu \mathrm{m}$ with a GSD of 2.28. Following melt blowing, the melt-blown SP/PBT(70/30) fibers were soaked in distilled water at $60{ }^{\circ} \mathrm{C}$ without stirring. After soaking 3 times ( 2 hours each time) followed by air-drying in a hood, we achieved PBT nanofibers with a geometric average diameter $\left(d_{\mathrm{N}, \mathrm{av}}\right)$ of $82 \mathrm{~nm}$ and a large aspect ratio (length/diameter $\left.>10^{3}-10^{5}\right)$, as shown in Figure 2(b). By DSC the crystallinity of the nanofibers was very similar to that of PBT microfibers: $X_{\mathrm{c} \text {,extracted PBT nanofibers }} \approx 30 \%$ vs. $X_{\mathrm{c} \text {,pure melt-blown PBT microfibers }} \approx 32 \%$.

Much smaller PBT nanofibers were obtained from the SP/PBT(70/30) blend than from the PS/PBT blend ( 82 vs. $200-250 \mathrm{~nm}$ ),[20] which we attribute to the smaller droplet size in the blend that was fed to the melt blowing apparatus. However, it is still challenging to establish the size correlation among the starting droplet size of the minor phase in the blend, the as-processed melt-blown fiber, and the final extracted nanofibers. For example, increasing the volume fraction of the minor phase (PBT or ECTFE) from 5\% to 30\% had no effect on the size of the asprocessed microfibers. However, the size of the PBT nanofibers extracted from melt blown PS/PBT blends increased from about $100 \mathrm{~nm}$ to $160 \mathrm{~nm}$, while that of the ECTFE nanofibers from melt blown PS/ECTFE blends appeared to be insensitive to the increase of the ECTFE volume fraction in the PS matrix, relatively stable at $90 \mathrm{~nm} .[36]$ 


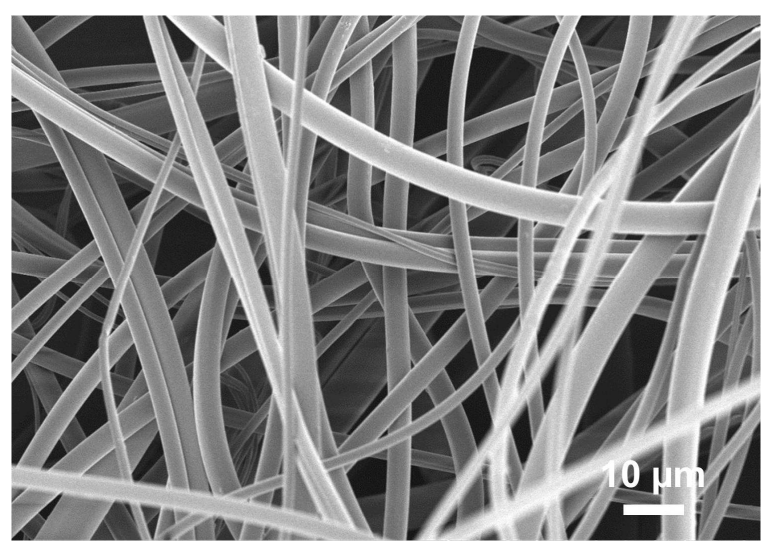

(a)

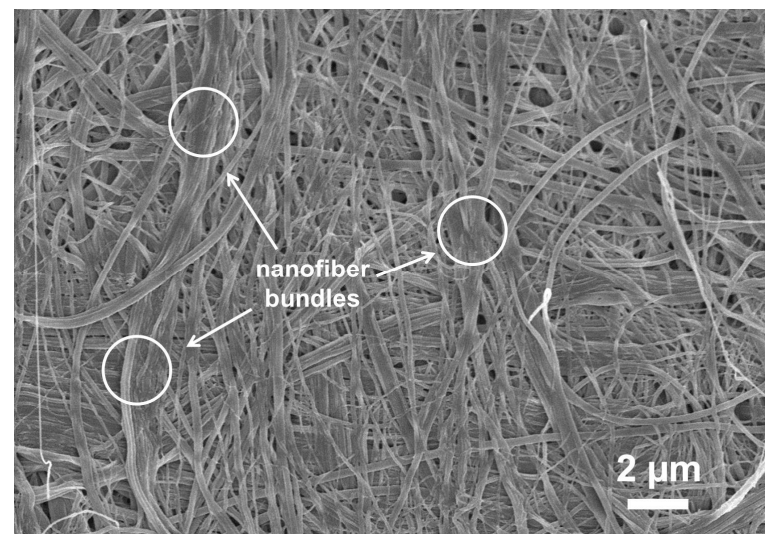

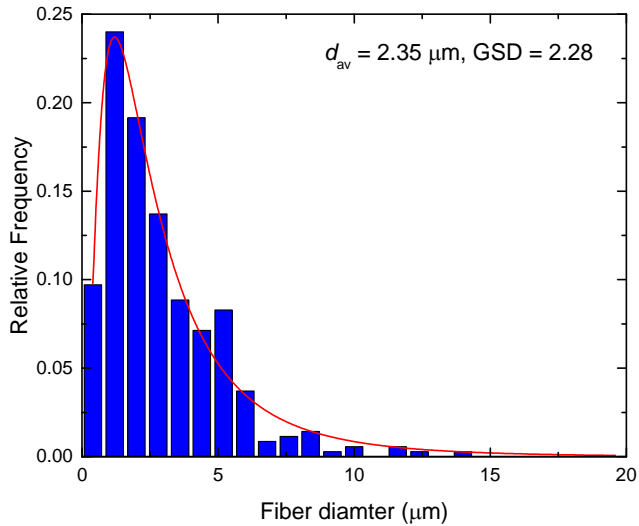

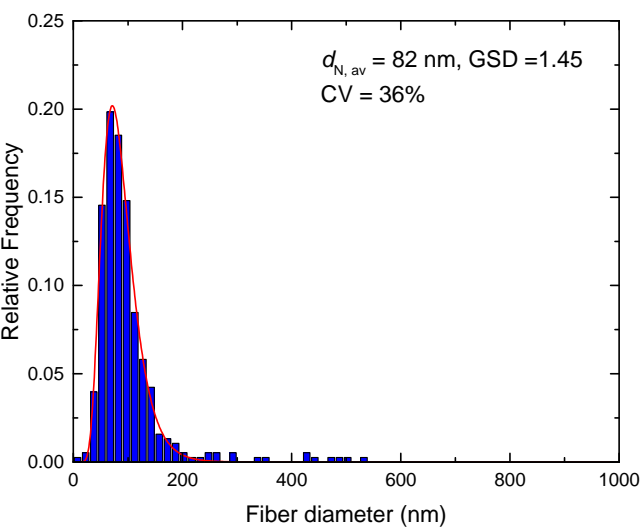

(b)

Figure 2. Fiber morphology and the corresponding diameter distribution of (a) melt-blown SP/PBT(70/30) fibers, and (b) PBT nanofibers obtained following removal of the carrier SP polymer with water.

Many of the nanofibers appearing in Figure 2 (b) are entrained in bundles, similar to what we reported for PBT nanofibers derived from THF-extracted melt-blown PS/PBT fibers.[20] Similar fiber bundles are found in melt spun island-in-the-sea fibers after removing the "sea" polymer.[37-44] We decreased the weight fraction of PBT (5 wt $\%, 10 \mathrm{wt} \%)$ in the SP matrix (SP/PBT(95/05), SP/PBT(90/10)) and obtained melt-blown microfibers $\left(d_{\mathrm{av}} \sim 1 \mu \mathrm{m}\right)$, as shown in Figure 3 (a) and (b). The lowest concentration blend, SP/PBT(95/05), resulted in $d_{\mathrm{N}, \mathrm{av}}=66 \mathrm{~nm}$ 
For Table of Contents use only

\section{Nanofibers from Water-Extractable Melt-Blown Immiscible Polymer Blends}

Zaifei Wang, Xiaotun Liu, Christopher W. Macosko*, Frank S. Bates*

Department of Chemical Engineering and Materials Science, University of Minnesota, Minneapolis, MN 55455

* Address correspondence to: macosko@umn.edu, bates001@umn.edu.

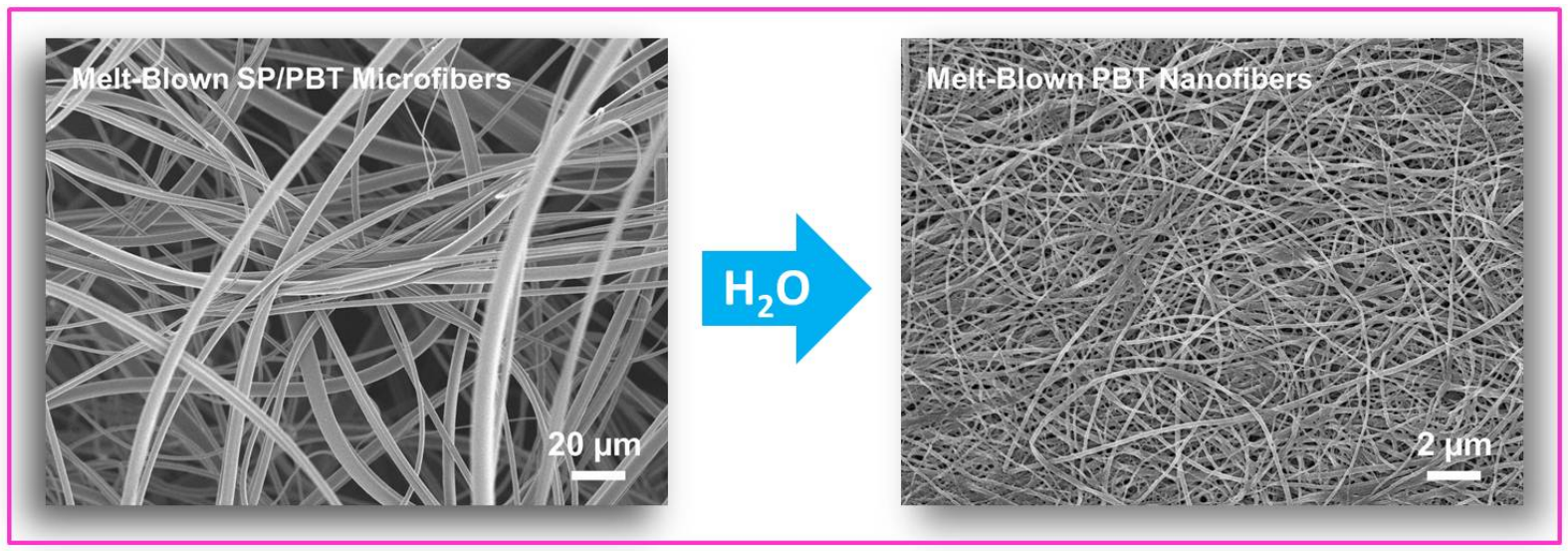


nanofibers after washing, along with some droplets/ellipsoids ( see Figure 3 (c)) and occasionally $0.5 \mu \mathrm{m}$ diameter sinusoidal fibers (see Supporting Information) indicative of fiber breakup.[4548] In contrast, the extracted materials from melt-blown SP/PBT(90/10) and SP/PBT(70/30) are largely devoid of these spurious structures with $d_{\mathrm{N}, \mathrm{av}}=70-80 \mathrm{~nm}$, which implies that increasing the minor phase concentration can facilitate the nanofiber formation. Moreover, it appears that lowering the minor phase concentration greatly reduces, but does not completely eliminate, nanofiber bundling, as can be seen by comparing Figures 2 (b) and 3 (d). We hypothesize that a combination of the steric constraints associated with the initially clustered nanofibers associated with the entangled microfibers, exacerbated by inter-fiber cohesion due to van der Waals forces, contribute to the occurrence of nanofiber bundles.[49-51] We are currently investigating approaches to reduce bundling.
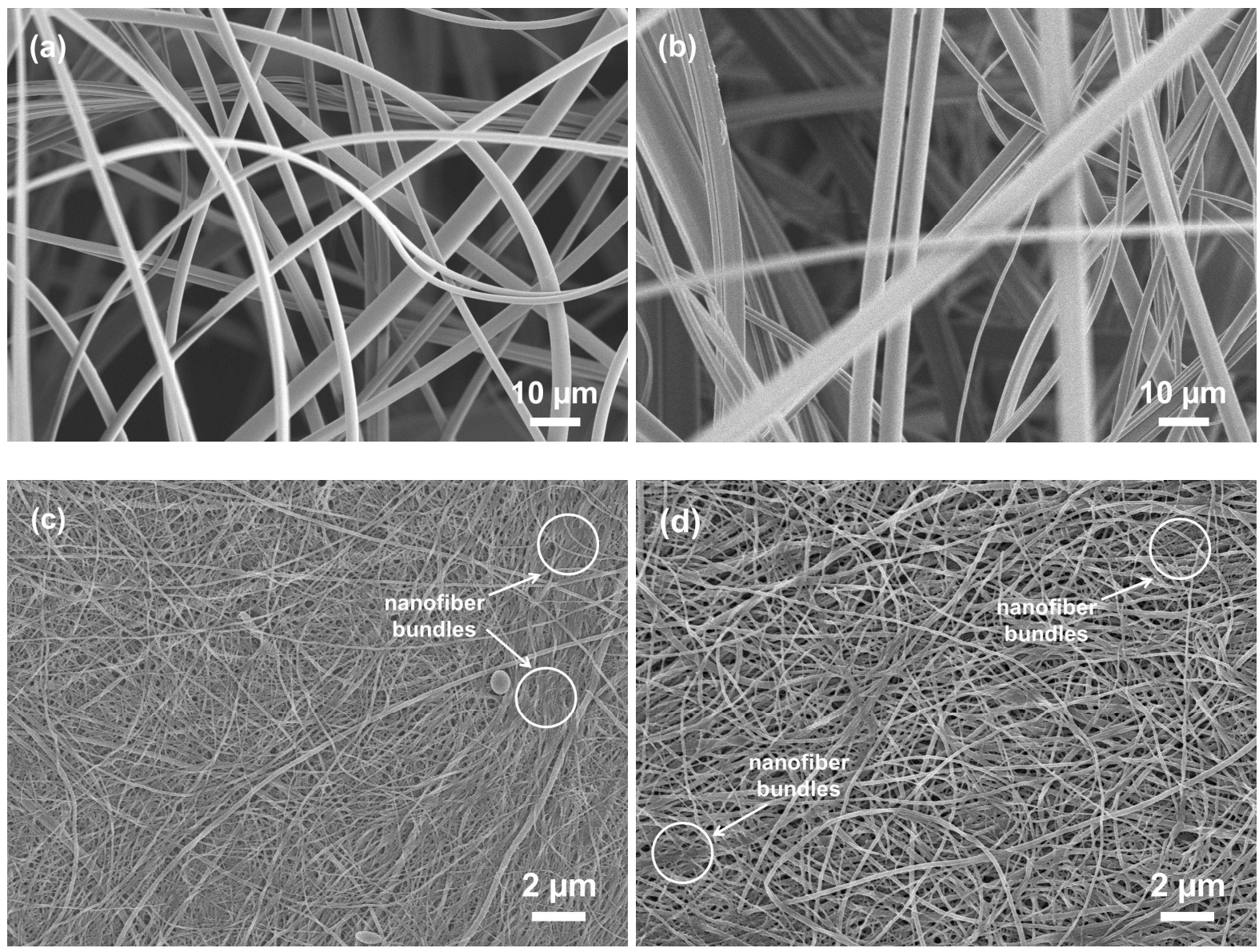
Figure 3. SEM images showing the morphology of (a) melt-blown SP/PBT(95/05) fibers, $d_{\mathrm{av}}=$ $1.60 \mu \mathrm{m}, \mathrm{GSD}=1.84$; (b) melt-blown SP/PBT(90/10) fibers, $d_{\mathrm{av}}=1.80 \mu \mathrm{m}, \mathrm{GSD}=1.93$; (c) water-extracted PBT nanofibers from melt-blown SP/PBT(95/05), $d_{\mathrm{N}, \mathrm{av}}=66 \mathrm{~nm}, \mathrm{GSD}=1.31$; (d) water-extracted PBT nanofibers from melt-blown SP/PBT(90/10), $d_{\mathrm{N}, \text { av }}=71 \mathrm{~nm}, \mathrm{GSD}=1.59$.

Fabrication of nanofibers through melt blowing immiscible polymer blends followed by water-extraction not only eliminates issues associated with organic solvents but also provides a new route to prepare multilayer melt-blown nano-/micro-fiber mats. We implemented this strategy by preparing a double-layer PBT nano-/micro-fiber composite. The SP/PBT(70/30) blend was melt blown and collected on top of a pre-made melt-blown PBT fiber mat, forming a double-layer microfiber mat. Then, we washed away the SP phase of the top layer by soaking the double-layer mat in distilled water, exposing the PBT nanofibers. After air-drying, we achieved a double-layer composite fiber mat comprised of PBT nanofibers $\left(d_{\mathrm{N}, \mathrm{av}}=82 \mathrm{~nm}\right)$ on top of PBT microfibers $\left(d_{\mathrm{av}} \approx 2 \mu \mathrm{m}\right)$, as demonstrated in the SEM image in Figure 4 (a).

However, as shown in Figure 4 (b), the top layer of the PBT nanofibers are so dense that the porous structure of the overall fiber mat is compromised, which detracts from potential applications in filtration media. One approach to maintaining the open porous structure of the double-layer composite is to decrease the density of the top PBT nanofiber mat. By decreasing the collection time of the melt-blown SP/PBT(70/30) fibers from 3 rotations of the drum collector (rotating at $0.5 \mathrm{rpm}$ ) to 1 rotation we were able to decorate the microfiber substrate with a porous layer of PBT nanofibers upon removing the SP carrier polymer, as shown in Figure 4 (c) and (d). Yet the nanofiber bundling and consolidation of the structure by further post processing are still issues to be addressed in the future after which this porous double-layer nano-/microfiber composite can function as filtration media. 

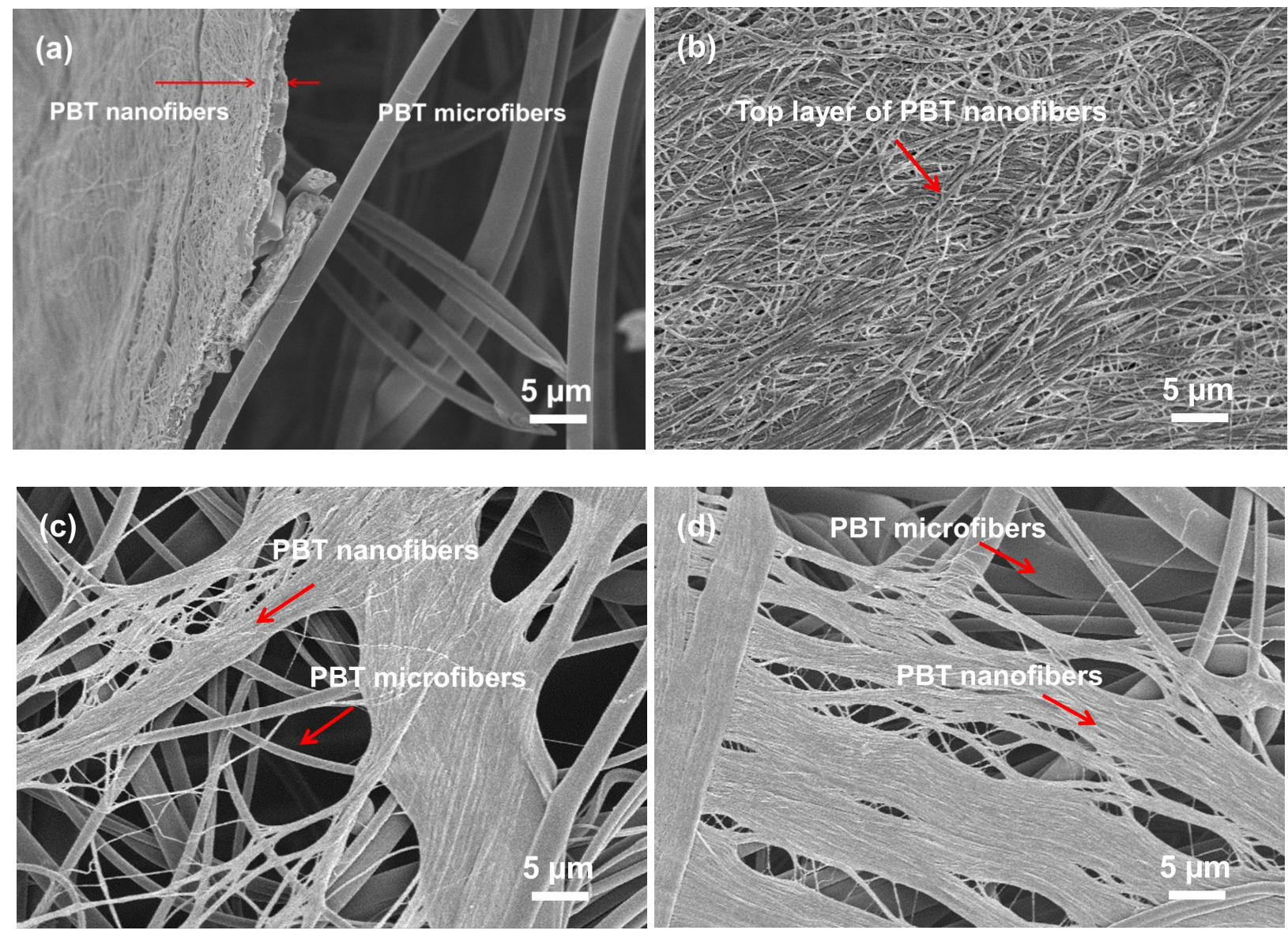

Figure 4. SEM images of (a) the side view of a double-layer nano-/micro-fiber composite where the top nanofiber layer was obtained by water-extraction of the melt-blown SP/PBT fibers collected for 3 rotations, (b) the top view of the nanofiber layer, (c) and (d) the top views of the double-layer composite demonstrating the overall porous structure after the collection was decreased from 3 rotations to 1 rotation.

\section{Conclusion}

In summary, we report here that nanofibers can be achieved from water-extractable meltblown immiscible polymer blends containing a commercial sulfopolyester (SP) as the sacrificial phase. Application of water-dispersible SP eliminates issues associated with organic solvents, providing a facile, economic, and environment-friendly approach to high throughput fabrication of melt-blown nanofibers with an average diameter as small as $66 \mathrm{~nm}$. Breakup and coalescence 
play key roles in nanofiber formation. Moreover, the water-based process offers a new route to prepare multilayer melt-blown nano-/micro-fiber composites as demonstrated with PBT. By tuning the collection time of the melt-blown SP/PBT blend fibers the density and thickness of the top layer of PBT nanofibers can be varied, with potential for use in filtration media.

\section{Acknowledgements}

The authors gratefully acknowledge Cummins Filtration for financial support. Sulfopolyester was kindly provided by Dr. Jeff Galloway at the Eastman Chemical Company. SEM was carried out in the Characterization Facility, University of Minnesota, which receives partial support from the National Science Foundation through the Materials Research Science and Engineering Center (NSF-MRSEC) program.

\section{References}

[1] I.M. Hutten, Processes for Nonwoven Filter Media, Handbook of Nonwoven Filter Media, Elsevier, Burlington, MA, 2007, pp. 195-244.

[2] Z. Wang, L. Espín, F.S. Bates, S. Kumar, C.W. Macosko, Water droplet spreading and imbibition on superhydrophilic poly(butylene terephthalate) melt-blown fiber mats, Chem. Eng. Sci. 146 (2016) 104-114.

[3] Z. Wang, C.W. Macosko, F.S. Bates, Tuning Surface Properties of Poly(butylene terephthalate) Melt Blown Fibers by Alkaline Hydrolysis and Fluorination, ACS Appl. Mater. Interfaces 6 (14) (2014) 11640-11648. 
[4] Z. Wang, C.W. Macosko, F.S. Bates, Fluorine-Enriched Melt-Blown Fibers from Polymer Blends of Poly(butylene terephthalate) and a Fluorinated Multiblock Copolyester, ACS Appl. Mater. Interfaces 8 (1) (2016) 754-761.

[5] S. Jinka, R. Behrens, C. Korzeniewski, V. Singh, A. Arunachalam, S. Parameswaran, G. Coimbatore, R. Kendall, R. Wolf, S. Ramkumar, Atmospheric Pressure Plasma Treatment and Breathability of Polypropylene Nonwoven Fabric, J. Ind. Text. 42 (4) (2013) 501-514.

[6] F. Çeken, Ü.H. Erdoğan, O. Kayacan, Ş.S. Uğurlu, Electromagnetic Shielding Efficiency of Nonwoven Insulation Panels Designed with Recycled Textiles and Copper Wires, J. Text. Inst. 103 (6) (2011) 669-675.

[7] L.H. Catalani, G. Collins, M. Jaffe, Evidence for Molecular Orientation and Residual Charge in the Electrospinning of Poly(butylene terephthalate) Nanofibers, Macromolecules 40 (5) (2007) 1693-1697.

[8] T.B.F. Woodfield, J. Malda, J. de Wijn, F. Péters, J. Riesle, C.A. van Blitterswijk, Design of Porous Scaffolds for Cartilage Tissue Engineering using A Three-Dimensional Fiber-Deposition Technique, Biomaterials 25 (18) (2004) 4149-4161.

[9] S. Agarwal, J.H. Wendorff, A. Greiner, Progress in the Field of Electrospinning for Tissue Engineering Applications, Adv. Mater. 21 (32-33) (2009) 3343-3351.

[10] A. Abou-Okeil, A.M. Sheta, A. Amr, M.A. Ali, Wound Dressing Based on Nonwoven Viscose Fabrics, Carbohydr. Polym. 90 (1) (2012) 658-666.

[11] Ching Wen Lou, C.-M. Lin, W.-H. Hsing, A.-P. Chen, J.-H. Lin, Manufacturing Techniques and Electrical Properties of Conductive Fabrics with Recycled Polypropylene Nonwoven Selvage, Text. Res. J. 81 (13) (2011) 1331-1343. 
[12] Z.M. Huang, Y.Z. Zhang, M. Kotaki, S. Ramakrishna, A Review on Polymer Nanofibers by Electrospinning and Their Applications in Nanocomposites, Compos. Sci. Technol. 63 (15) (2003) 2223-2253.

[13] D. Li, Y. Wang, Y. Xia, Electrospinning of Polymeric and Ceramic Nanofibers as Uniaxially Aligned Arrays, Nano Lett. 3 (8) (2003) 1167-1171.

[14] M. Bognitzki, W. Czado, T. Frese, A. Schaper, M. Hellwig, M. Steinhart, A. Greiner, J.H. Wendorff, Nanostructured Fibers via Electrospinning, Adv. Mater. 13 (1) (2001) 70-72.

[15] T. Huang, L.R. Marshall, J.E. Armantrout, S. Yembrick, W.H. Dunn, J.M. Oconnor, T. Mueller, M. Avgousti, M.D. Wetzel, Production of Nanofibers by Melt Spinning, U.S. Patent 2008/0242171 A1, 2008, 12.

[16] S. Padron, A. Fuentes, D. Caruntu, K. Lozano, Experimental Study of Nanofiber Production Through Forcespinning, J. Appl. Phys. 113 (2) (2013) 024318.

[17] C.J. Ellison, A. Phatak, D.W. Giles, C.W. Macosko, F.S. Bates, Melt Blown Nanofibers: Fiber Diameter Distributions and Onset of Fiber Breakup, Polymer 48 (11) (2007) 3306-3316.

[18] C.J. Luo, S.D. Stoyanov, E. Stride, E. Pelan, M. Edirisinghe, Electrospinning versus Fibre Production Methods: from Specifics to Technological Convergence, Chem. Soc. Rev. 41 (13) (2012) 4708-35.

[19] A. Greiner, J.H. Wendorff, Electrospinning: A Fascinating Method for the Preparation of Ultrathin Fibers, Angew. Chem., Int. Ed. 46 (30) (2007) 5670-5703.

[20] F. Zuo, D.H. Tan, Z. Wang, S. Jeung, C.W. Macosko, F.S. Bates, Nanofibers from Melt Blown Fiber-in-Fiber Polymer Blends, ACS Macro Lett. 2 (4) (2013) 301-305. 
[21] N.H. An Tran, H. Brünig, C. Hinüber, G. Heinrich, Melt Spinning of Biodegradable Nanofibrillary Structures from Poly(lactic acid) and Poly(vinyl alcohol) Blends, Macromol. Mater. Eng. 299 (2) (2014) 219-227.

[22] X. Jiang, T. Jiang, X. Zhang, X. Zhang, H. Dai, The Plasticizing Effect of Calcium Nitrate on Poly(vinyl alcohol), Polym. Eng. Sci. 53 (6) (2013) 1181-1186.

[23] J. Jang, D.K. Lee, Plasticizer Effect on The Melting and Crystallization Behavior of Polyvinyl Alcohol, Polymer 44 (26) (2003) 8139-8146.

[24] W. Wu, H. Tian, A. Xiang, Influence of Polyol Plasticizers on the Properties of Polyvinyl Alcohol Films Fabricated by Melt Processing, J. Polym. Environ. 20 (1) (2012) 63-69.

[25] X. Jiang, T. Jiang, X. Zhang, H. Dai, X. Zhang, Melt Processing of Poly(vinyl alcohol) Through Adding Magnesium Chloride Hexahydrate and Ethylene Glycol as A Complex Plasticizer, Polym. Eng. Sci. 52 (10) (2012) 2245-2252.

[26] M. Mohsin, A. Hossin, Y. Haik, Thermal and Mechanical Properties of Poly(vinyl alcohol) Plasticized with Glycerol, J. Appl. Polym. Sci. 122 (5) (2011) 3102-3109.

[27] T. Nishino, S.c. Kani, K. Gotoh, K. Nakamae, Melt Processing of Poly(vinyl alcohol) Through Blending with Sugar Pendant Polymer, Polymer 43 (9) (2002) 2869-2873.

[28] S. Kubo, J.F. Kadla, The Formation of Strong Intermolecular Interactions in Immiscible Blends of Poly(vinyl alcohol) (PVA) and Lignin, Biomacromolecules 4 (3) (2003) 561-567.

[29] H. Nishio, Microfibers-Generating Fibers and A Woven or Non-Woven Fabric Microfibers, U.S. Patent 5,290,626, 1994, 4.

[30] M.J. Caulfield, X. Hao, G.G. Qiao, D.H. Solomon, Degradation on Polyacrylamides. Part I. Linear Polyacrylamide, Polymer 44 (5) (2003) 1331-1337. 
[31] C.A. Fyfe, M.S. McKinnon, Investigation of The Thermal Degradation of Poly(acrylic acid) and Poly(methacrylic acid) by High-Resolution Carbon-13 CP/MAS NMR Spectroscopy, Macromolecules 19 (7) (1986) 1909-1912.

[32] C. Lau, Y. Mi, A Study of Blending and Complexation of Poly(acrylic acid)/Poly(vinyl pyrrolidone), Polymer 43 (3) (2002) 823-829.

[33] S. Han, C. Kim, D. Kwon, Thermal/Oxidative Degradation and Stabilization of Polyethylene Glycol, Polymer 38 (2) (1997) 317-323.

[34] S. Wu, Formation of Dispersed Phase in Incompatible Polymer Blends: Interfacial and Rheological Effects, Polym. Eng. Sci. 27 (5) (1987) 335-343.

[35] D.H. Tan, C. Zhou, C.J. Ellison, S. Kumar, C.W. Macosko, F.S. Bates, Meltblown Fibers: Influence of Viscosity and Elasticity on Diameter Distribution, J. Non-Newtonian Fluid Mech. $165(15-16)(2010) 892-900$.

[36] Z. Wang, Producing Melt Blown Nano-/Micro-Fibers with Unique Surface Wetting Properties, Ph.D. Thesis University of Minnesota Twin Cities, Minneapolis, MN, 2015.

[37] X. Zhang, G. Jin, W. Ma, L. Meng, H. Yin, Z. Zhu, Z. Dong, R. Wang, Fabrication and Properties of Poly(l-lactide) Nanofibers via Blend Sea-Island Melt Spinning, J. Appl. Polym. Sci. 132 (1) (2015) DOI: 10.1002/app.41228.

[38] P. Zhang, D. Xu, R. Xiao, Morphology Development and Size Control of PA6 Nanofibers from PA6/CAB Polymer Blends, J. Appl. Polym. Sci. 132 (27) (2015) DOI: 10.1002/app.42184.

[39] B. Yeom, B. Pourdeyhimi, Aerosol Filtration Properties of PA6/PE Islands-in-The-Sea Bicomponent Spunbond Web Fibrillated by High-Pressure Water Jets, J Mater Sci 46 (17) (2011) $5761-5767$. 
[40] X. Si, L. Guo, Y. Wang, K.-t. Lau, Preparation and Study of Polypropylene/Polyethylene Terephthalate Composite Fibres, Compos. Sci. Technol. 68 (14) (2008) 2943-2947.

[41] M. Li, R. Xiao, G. Sun, Preparation of Polyester Nanofibers and Nanofiber Yarns from Polyester/Cellulose Acetate Butyrate Immiscible Polymer Blends, J. Appl. Polym. Sci. 124 (1) (2012) 28-36.

[42] M. Li, R. Xiao, G. Sun, Formation and Morphology Development of Poly(butylene terephthalate) Nanofibers from Poly(butylene terephthalate)/Cellulose Acetate Butyrate Immiscible Blends, Polym. Eng. Sci. 51 (5) (2011) 835-842.

[43] D. Wang, G. Sun, L. Yu, Recyclability of Cellulose Acetate Butyrate (CAB) Matrix for Controllable and Productive Fabrication of Thermoplastic Nanofibers, Carbohydrate Polymers 83 (3) (2011) 1095-1100.

[44] D. Wang, G. Sun, B.-S. Chiou, A High-Throughput, Controllable, and Environmentally Benign Fabrication Process of Thermoplastic Nanofibers, Macromol. Mater. Eng. 292 (4) (2007) 407-414.

[45] T. Semba, K. Kitagawa, M. Nakagawa, U. Semo Ishiaku, H. Hamada, Study on Morphology Development for In Situ Fiber-Reinforced Composites by Blending Polyolefin and Polycaprolactone, J. Appl. Polym. Sci. 98 (1) (2005) 500-508.

[46] C.L. Tucker III, P. Moldenaers, Microstructural Evolution in Polymer Blends, Annu. Rev. Fluid Mech. 34 (1) (2002) 177-210.

[47] C. Dae Han, K. Funatsu, An Experimental Study of Droplet Deformation and Breakup in Pressure - Driven Flows through Converging and Uniform Channels, J. Rheol. (Melville, NY, U. S.) $22(2)(1978) 113-133$. 
[48] P. Van Puyvelde, H. Yang, J. Mewis, P. Moldenaers, Breakup of Filaments in Blends During Simple Shear Flow, J. Rheol. (Melville, NY, U. S.) 44 (6) (2000) 1401-1415.

[49] R. Nayak, I.L. Kyratzis, Y.B. Truong, R. Padhye, L. Arnold, Structural and Mechanical Properties of Polypropylene Nanofibres Fabricated by Meltblowing, J. Text. Inst. (2014) 1-12.

[50] D. Langbein, Van der Waals Attraction Between Cylinders, Rods or Fibers, Phys. Kondens. Mater. 15 (1) (1972) 61-86.

[51] H.J. Oh, S.H. Han, S.S. Kim, A novel method for a high-strength electrospun meta-aramid nanofiber by microwave treatment, J. Polym. Sci., Part B: Polym. Phys. 52 (12) (2014) 807-814. 